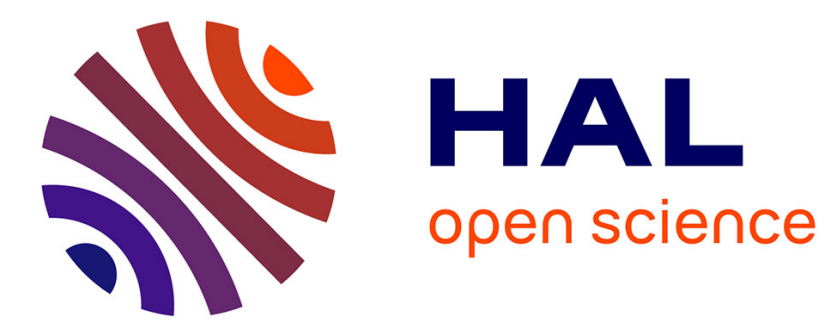

\title{
Compensation in intergroup relations: An investigation of its structural and strategic foundations
}

Laurent Cambon, Vincent Yzerbyt, Sonya Yakimova

\section{To cite this version:}

Laurent Cambon, Vincent Yzerbyt, Sonya Yakimova. Compensation in intergroup relations: An investigation of its structural and strategic foundations. British Journal of Social Psychology, 2015, 54 (1), pp.140-158. 10.1111/bjso.12067 . hal-01881504

\section{HAL Id: hal-01881504 \\ https://hal.univ-cotedazur.fr/hal-01881504}

Submitted on 26 Sep 2018

HAL is a multi-disciplinary open access archive for the deposit and dissemination of scientific research documents, whether they are published or not. The documents may come from teaching and research institutions in France or abroad, or from public or private research centers.
L'archive ouverte pluridisciplinaire HAL, est destinée au dépôt et à la diffusion de documents scientifiques de niveau recherche, publiés ou non, émanant des établissements d'enseignement et de recherche français ou étrangers, des laboratoires publics ou privés. 
Running head: COMPENSATION IN INTERGROUP RELATIONS

Compensation in intergroup relations:

An investigation of its structural and strategic foundations

\author{
Laurent Cambon
}

Département de Psychologie, Université Nice-Sophia Antipolis, France

Vincent Y. Yzerbyt

Université catholique de Louvain, Center for the Study of Social Behavior, Belgium

Sonya Yakimova

Centre de Recherche en Psychologie, Cognition, Communication, Université Européenne de

Bretagne-Rennes 2, France

Please send correspondence to:

Laurent Cambon

Laboratoire d'Anthropologie et de Psychologie Cognitive et Sociale

Université de Nice-Sophia Antipolis

24 avenue des Diables Bleus

F-06357 Nice cedex 4 France

Email: cambon@unice.fr

or to

Vincent Yzerbyt

Centre d'Etude du Comportement Social

Université catholique de Louvain

Place du Cardinal Mercier 10

B-1348 Louvain-la-Neuve, Belgium

Email : vincent.yzerbyt@uclouvain.be 


\begin{abstract}
Recent work in intergroup relations stresses the role of two fundamental dimensions, competence and warmth, which organize the perception of social groups. A pattern often encountered in people's ratings is one of compensation in that a group that is evaluated higher than another group on one of the two fundamental dimensions is also judged lower on the other fundamental dimension. Based on Social Identity Theory, the present work extends previous research on compensation by examining boundary conditions as well as underlying psychological processes. Two studies involving experimental and correlational evidence, minimal and real groups, and different kinds of conflict, reveal that compensation is more likely when the groups are in asymmetrical relation and share a cooperative view of the intergroup setting. Our data also suggest that, among members of low status groups, compensation is associated with social creativity. In contrast, and in line with the "noblesse oblige' effect, members of high status group would seem to rely on compensation as a means to appear non-discriminatory.
\end{abstract}

Key words: compensation, competence, warmth, intergroup relations, ingroup bias. 
The compensation effect in intergroup relations:

An investigation of its structural and strategic foundations

Research on intergroup relations reveals that groups are constantly comparing each other on a variety of aspects (for a review, see Yzerbyt \& Demoulin, 2010). For instance, Italians and Germans are quick to point to features that characterize each group in a way that seems complementary. Whereas Germans are hard-working and organized, Italians are sophisticated and know how to enjoy life. All seems to be going fine in a world where each group praises itself for qualities that the other group seems to be lacking. What are the factors ruling such seemingly harmonious relations? The present paper aims at investigating a series of factors that may facilitate if not condition the existence of what researchers have called a compensation effect (for a review, see Kervyn, Yzerbyt, \& Judd, 2010)

According to Social Identity Theory (SIT), the need for positive and distinctive social identity is at the heart of discrimination (Tajfel \& Turner, 1979). However, this claim should not be taken to mean that group members discriminate all the time on all possible dimensions. In fact, SIT holds that people's appraisal of social groups is constrained by their beliefs on the nature of the social structure. For example, Tajfel and Turner (1979) argued that when the social hierarchy is perceived as stable and legitimate, low-status groups should exhibit social creativity, that is, an agreement regarding the superiority of the high-status group on the dimension defining its dominance, while favoring the ingroup on a dimension of comparison not related to the status difference. Whereas Tajfel and Turner's analysis focused primarily on strategies adopted by members of low-status groups, SIT theorists have also dealt with the strategies used by high-status groups (van Knippenberg \& Ellemers, 1990). For these groups, systematic discrimination is also not the rule and a form of magnanimity, also known as the 'noblesse oblige' effect (Sachdev \& Bourhis, 1985; Vanbeselaere, Boen, Van Avermaet, \& 
Buelens, 2006), sometimes emerges in stable intergroup contexts. Specifically, high-status group members show ingroup bias on the status-defining dimensions but manifest no bias or even an outgroup bias on the status-irrelevant dimensions (Bettencourt, Dorr, Charlton, \& Hume, 2001; Mullen, Brown, \& Smith, 1992; Terry, 2003; Turner \& Brown, 1978).

Although SIT has generally remained silent as to the exact nature of these dimensions, recent work conducted in the framework of the stereotype content model (see Cuddy, Fiske \& Glick, 2008; Fiske, Cuddy \& Glick, 2007) suggests that the domains in which high- and lowstatus groups pursue positive distinctiveness are respectively the competence and warmth domains (Oldmeadow \& Fiske, 2010; Richetin, Durante, Mari, Perugini, \& Volpato, 2012). Moreover, it has been argued that judgments on these two fundamental dimensions often turn out to be negatively correlated in such a way as to combine ingroup favouritism on one dimension and outgroup favouritism on the other dimension, a pattern known as compensation (Judd, James-Hawkins, Yzerbyt, \& Kashima, 2005; Yzerbyt, Provost, \& Corneille, 2005; Yzerbyt, Kervyn, \& Judd 2008; for a review, see Kervyn et al., 2010). Interestingly, compensation theorists interpreted compensation as the manifestation of social creativity and magnanimity strategies respectively for low- and high-status groups, and showed that it works uniquely for the competence and warmth dimensions (Yzerbyt et al., 2008). However, the work to date remains silent as to the social conditions in which compensation could characterize an intergroup relation. Thus, the first aim of this paper is to delineate the socio-structural contexts under which compensation could appear. The second aim relates to the creativity and magnanimity strategies. To date no direct empirical evidence has been gathered delineating the role of these strategies in the emergence of compensation. Such a demonstration constitutes our second aim. Structural conditions for the emergence of compensation 
From the above, it appears that in contrast to a systematic tendency to differentiate, compensation would seem to be a means to protect one's ingroup identity by maintaining an advantage on some dimension of importance while manifesting cooperation by acknowledging the outgroup superiority on another dimension. However, one would only expect this effect to emerge when intergroup relations are cooperative and we predict that compensation is unlikely to emerge in the context of competitive group relations. As a matter of fact, several research efforts in the SIT tradition show that patterns of creativity and magnanimity appear more readily when the intergroup relations are perceived as stable and legitimate, that is, when the relations are not competitive (Terry, 2003). Along similar lines, van Knippenberg (1984) has argued that, in the context of social cooperation, the evaluation of outgroup characteristics need not be derogatory and that two groups could even agree about each group's dimensional superiority.

To our knowledge, no work has been specifically devoted to this prediction. We manipulated the degree of conflict and hypothesized that there should be more compensation when the level of conflict is low than when it is high. In contrast, groups in conflict should more readily demonstrate ingroup bias on both dimensions.

Next to outright conflict, other factors which could influence a cooperative view of the world are the stability and legitimacy of the social structure (Bettencourt \& Bartholow, 1998; Turner \& Brown, 1978; Vaughan, 1978). As has often been argued in the SIT literature (Tajfel \& Turner, 1979; Turner, 1999), the perception of the stability and legitimacy of the existing social structure is a powerful determinant of intergroup relations. Research suggests that the coupling of perceived illegitimacy and instability of a given status system provides the most influential impetus for the rejection of the status hierarchy and, as a way of consequence, has a negative impact on intergroup relations and likely prompts competition (Turner \& Brown, 1978; Vaughan, 1978). Only if some difference between two groups is 
thought to be stable and legitimate will group members be inclined to refrain from competing with the outgroup. In such a situation, the members of the high-status group should feel positive and securely positioned at the top of the social hierarchy. As a result, they should manifest ingroup bias on the dimension pertaining to the status difference (e.g., competence) and magnanimity toward the low-status group on the dimension unrelated to the status difference (e.g., warmth). As for the members of the low-status group, they should hardly question the superiority of the outgroup and acknowledge their inferior status thus showing an outgroup bias on the dimension related to the difference (e.g., competence). In fact, they should try to gain positivity by favoring their group on the dimension unrelated to the critical group difference (e.g., warmth).

In the present manuscript, we tested this conjecture by manipulating the difference between the status of the two groups as a proxy for legitimacy and stability (Bettencourt \& Bartholow, 1998). We reasoned that the larger the status difference between the two groups, the more group members should see the difference as legitimate and stable. This means that when the difference between the groups is large, a compensation pattern should be more readily observed. In contrast, compensation should be less present when the difference between the groups is moderate, making the social hierarchy appear less legitimate and stable.

A final and related condition for compensation is the existence of an asymmetrical relation between two groups on one of the fundamental dimension. Clearly, if there is an $a$ priori equality between groups, there should be little need to compensate. As preliminary support for this idea, Reichl (1997) found that members of equal status groups did not make a difference between groups on their evaluation on the two dimensions whereas such a difference was observed among members of low- and high-status groups. Also, Brewer, Manzi, and Shaw (1993) reported that whereas low- and high-status (minority) groups showed what we would call a compensatory pattern, no such pattern emerged with equal 
status groups. Here, we manipulated the (degree of) status difference between the groups on one dimension. We hypothesized that compensation would emerge more readily when a difference was assumed to exist between the groups.

The phenomenology of compensation

According to SIT, if a group is credited with less value than another on some dimension of comparison, and if this inferiority is indisputable (i.e., if there is no conflict or if the difference between the groups is perceived to be stable and legitimate), the members of the low-status group will nevertheless suffer from the inferiority (Ellemers \& Van Rijswijk, 1997; Tajfel \& Turner, 1979). This feeling of low worth should drive compensation on a secondary dimension, a strategy which can be seen as a form of social creativity. This process should show at the correlational level by way of a negative correlation between the ratings of the ingroup on the two dimensions. As for the members of high-status groups, we propose to conceive compensation as a reflection of some form of magnanimity, also known as the 'noblesse oblige' (Vanbeselaere et al., 2006). That is, to the extent that the members of the high-status group feel securely positioned at the top of the hierarchy, i.e., that the difference between high- and low-status is perceived as stable and legitimate on some dimension of relevance, they should be willing to concede superiority to the members of the low-status group on those aspects that are irrelevant to the key comparison dimension. Such magnanimity should give rise to a positive correlation between the ratings of the ingroup on one dimension and the ratings of the outgroup on the other.

\section{Studies $1 \mathrm{a}$ and $1 \mathrm{~b}$}

In Studies 1a and 1b, we manipulated the focal dimension of interest (competence in Study 1a versus warmth in Study 1b), and assessed participant's rating on both dimensions ${ }^{1}$. We also manipulated the relative status of the groups (asymmetrical versus symmetrical status) and the presence of conflict between the groups (conflict absent versus present). Our 
main hypothesis dealt with the conditions of emergence of compensation, i.e., relative status and conflict, and was tested in both Studies 1a and 1b. We also began to address the process hypotheses spelled out above.

Method

\section{Participants}

The sample consisted of 337 psychology students recruited for partial course credit. Seven cases had to be omitted because they doubted the manipulation. The final sample consisted of $N=330$ ( $N=166$ and $N=164$, for Studies 1a, and 1b respectively). Ages ranged between 18 and 43 years $(M=23.1 ; S D=3.14$; females=78\%).

\section{Procedure and design}

A male or a female experimenter (a post-hoc analysis revealed that the sex of the experimenter had no effect, all $F_{s}<1$ ) introduced the experiment as an investigation on group discussion and on the role of competence (in Study 1a)/warmth (In Study 1b) in small group interactions. Participants came to the experiment in session of four or six persons, filled in a bogus test in order to assess their competence/warmth, and were categorized into one of two groups according to their competence/warmth score. A pretest ensured that the tests came across as plausible competence/warmth tests and were ambiguous enough to prevent participants from making a realistic estimate of their score. After the experimenter had allegedly scored the test, she/he provided public feedback about participants' competence/warmth. In the asymmetrical condition, one half of the participants in the session received low scores whereas the other half received high scores. In the symmetrical condition, all participants in the session received either a high or a low score.

Participants were then divided in two groups. In the asymmetrical condition, one group comprised all high scorers whereas the other group comprised all low scorers. In the symmetrical condition, the division was ostensibly random. The two groups were then led to 
two different rooms and asked to fill in a questionnaire assessing their attitude on the 'role of psychoanalysis in psychology course', a topic allegedly selected for the forthcoming group task. Actually, we used this topic as a means to manipulate conflict between the two groups because a pretest revealed that first year psychology students were rather positively inclined towards psychoanalysis. In the conflict condition, we gave participants bogus feedback that the outgroup thought that psychoanalysis is useless and even detrimental. In the no-conflict condition, participants learned that the outgroup held the same (presumably positive) attitude towards psychoanalysis as the ingroup.

Next, participants in both groups completed a booklet containing the dependent variables and manipulation check questions. Participants were then debriefed.

Participants were randomly assigned to a 2 (relation: asymmetrical vs. symmetrical) $\mathrm{x}$ 2 (conflict: presence vs. absence) x 2 (status: high vs. low) between-subjects design in each experiment.

\section{Measures}

A relative status question asked participants the extent to which they thought that the ingroup had a lower $(=1)$ versus higher $(=9)$ competence/warmth than the outgroup.

Four questions (e.g., 'Do you feel hostility toward the other group?') assessed the perception of a conflict on 9-point scales with 1 (9) corresponding to the perception of a weak (strong) conflict ( $\alpha \mathrm{s}=.89$ for Studies 1a and $1 \mathrm{~b}$ ).

Finally, participants rated the ingroup and the outgroup on 12 positive and negative competence and warmth traits (see Yzerbyt et al., 2008) ${ }^{2}$ on a 9-point scale ranging from 1 (= not at all) to 9 (= totally). Traits were presented in a random fixed order. In order to facilitate a comparative judgment and to avoid counterbalancing the order of the descriptions, participants rated each group on the same scale, using an "I" to tick the scale when describing their 'i'ngroup and an "O" when describing the 'o'utgroup. 
Results

For each experiment, we computed a global score for each dimension by averaging the ratings on the three positive traits and the (reversed) ratings on the three negative traits (see Tables 1a, and 1b, for the raw means). Cronbach's alphas ranged from .66 to .94 .

\section{Preliminary analyses}

We first submitted participants' answers to the relative status question to a 2 (conflict: presence vs. absence) x 2 (relation: asymmetrical vs. symmetrical) x 2 (status: high vs. low) ANOVA. The status main effects, all $F s>257.36, p<.001$, confirmed the success of our manipulation. Participants perceived themselves as having higher status $\left(M_{1 a}=5.93, M_{1 b=6.56}\right)$ in the high than in the low status conditions $\left(M_{1 a}=3.51, M_{1 b=3.48}\right)$.

Next, we submitted the average score of perception of conflict to similar ANOVAs. The main effects of conflict proved significant, all $F s>411.01$, ps $<.001$, confirming that participants in the conflict conditions perceived the situation as much more conflicting $\left(M_{1 a}=6.10, M_{1 b=5.79}\right)$ than participants in the no conflict conditions $\left(M_{1 a}=2.81, M_{1 b=3.41}\right)$.

\section{Compensation versus ingroup bias}

We expected compensation to emerge more readily with asymmetrical intergroup relations and with an absence of conflict. In contrast, ingroup bias should show up across the board when a high level of conflict intrudes the intergroup relations. We tested these predictions by capitalizing on two indices. First, we computed a compensation index. If the difference between the ingroup and the outgroup on the manipulated dimension (competence in Study 1a, warmth in Study 1b) was positive then this difference was added to the difference between the outgroup and the ingroup on the non-manipulated dimension. In contrast, if the difference between the ingroup and the outgroup on the manipulated dimension was not positive then this difference was added to the difference between the ingroup and the outgroup on the non-manipulated dimension. The more positive the score, the more 
participants compensate. Second, we computed an ingroup bias index by adding the difference between the ingroup and the outgroup on warmth to the difference between the ingroup and the outgroup on competence. The more positive the score, the more participants expressed ingroup bias. Interestingly, these two indices were negatively correlated, $r_{\text {studyla }}(166)=-.47, p<.001 ; r_{\text {studylb }}(164)=-.56, p<.001$, and the analyses led to similar conclusions. We therefore decided to examine the relative impact of compensation versus ingroup bias by creating a combined index of preference for compensation for which we subtracted the index of ingroup bias from the index of compensation. A positive score corresponded to a preference for compensation over ingroup bias whereas a negative one signals a preference for ingroup bias over compensation. This index was submitted to a 2 (conflict: presence vs. absence) x 2 (relation: asymmetrical vs. symmetrical) x 2 (status: high vs. low) ANOVA.

The analysis for Study 1a revealed the presence of significant conflict and relation main effects, $F(1,158)=258.94, p<.001$, and $F(1,158)=70.10, p<.001$. Not surprisingly, a strong preference for ingroup bias emerged in the presence of conflict $(\underline{M}=-3.57)$ whereas compensation was preferred in the absence of conflict $(\underline{M=0.96) .}$. Also, whereas no tendency emerged when relations were asymmetrical $(\underline{M}=-0.12)$, ingroup bias clearly prevailed when relations were symmetrical $(\underline{M}=-2.48)$. In line with our hypotheses, these two main effects were qualified by a significant interaction between conflict and relation, $F(1,158)=8.43$, $p<.005$. Probing this interaction revealed that all mean differences were highly significant as indexed by a priori contrasts. As predicted, preference for compensation only appeared in the absence of conflict and in asymmetrical relations $(\underline{M}=2.56), t(44)=12.42, p<.001$. In all other conditions, the preference for compensation turned out to be negative revealing that participants opted for ingroup bias instead. Specifically, the preference for ingroup bias was of moderate intensity in the symmetrical and no-conflict condition $(\underline{M}=-0.63), t(40)=-4.71$, 
$p<.001$, but more marked in the asymmetrical conflict condition $(\underline{M}=-2.80), t(39)=-6.96$, $p<.001$, and extreme in the symmetrical conflict condition $(\underline{M}=-4.34), t(40)=-13.20, p<.001$.

In Study 1b, all three main effects proved significant. Again, a strong preference for ingroup bias emerged in the presence of conflict $(\underline{M}=-4.15)$ whereas compensation was preferred in the absence of conflict $(\underline{M}=0.81), F(1,156)=651.67, p<.001$. Ingroup bias was also more strongly preferred in the case of symmetrical relations $(\underline{M}=-2.05)$ than when relations were asymmetrical $(\underline{M}=-1.30), F(1,156)=14.92, p<.001$. Finally, there was more of a preference for ingroup bias among participants belonging to a low-status group $(\underline{M}=-1.96)$ than to a high-status group $(\underline{M}=-1.38), F(1,156)=8.68, p<.004$. In contrast to Study $1 \mathrm{a}$, the key interaction was not significant, $F(1,156)<1, n s$, but was in fact qualified by a three-way interaction, $F(1,156)=17.07, p<.001$. Probing this interaction revealed that preference for compensation was significant in the absence of conflict and in asymmetrical relations $\left(M_{h i g h-}\right.$ status $\left.=1.21, M_{\text {low-status }}=1.11\right)$ and that these two conditions tended to differ from the absence of conflict and symmetrical relation conditions $\left(M_{\text {high-status }}=0.50, M_{\text {low-status }}=0.42\right)\left(p_{\text {high-status }}<.06\right.$, $\left.p_{\text {low-status }}<.07\right)$. In the conflict conditions, all four means were strongly negative thus revealing the presence of a marked preference for ingroup bias $\left(M_{\text {symmetrical-high-status }}=-4.83, M_{\text {symmetrical-low- }}\right.$ status $\left.=-4.27, M_{\text {asymmetrical-high-status }}=-2.41, M_{\text {asymmetrical-low-status }}=-5.08\right)$.

\section{Correlational evidence}

In order to further examine the phenomenology of compensation, correlational analyses were conducted separately for low- and high-status group conditions. In light of the above findings, we only examined responses in the asymmetrical and non-conflicting relations conditions.

Turning to low-status groups first, we correlated participants' trait attribution to their ingroup on the manipulated dimension (competence in Study 1a, warmth in Study 1b) with their trait attribution to the ingroup on the non-manipulated dimension (warmth in Study 1a, 
competence in Study 1b). As predicted, the correlation was negative and significant in both cases, $r_{\text {study } 1 a}(23)=-.45, p<.04 ; r_{\text {study } l b}(22)=-.50, p<.01$. We also checked whether ingroup bias on the manipulated dimension was negatively correlated with ingroup bias on the nonmanipulated dimension. This was indeed the case, $r_{\text {study } 1 a}(23)=-.59, p<.003$ and $r_{\text {study } 1 b}(22)=-$ $.44, p<.04$.

Turning to the high-status participants, our data confirmed the presence of the 'noblesse oblige' pattern in the absence of conflict and asymmetrical relation, that is, these participants' attributions of competence (Study 1a)/warmth (Study 1b) to the ingroup were correlated with their attributions of the other dimension to the low-status group, $r_{\text {study }}$ ${ }_{1 a}(22)=.71, p<.001, r_{\text {study } 1 b}(20)=.73, p<.001$. In contrast, no such pattern emerged in the other conditions (all $r<.15$ ).

Discussion

As a set, these studies send a strong message: A clear preference for compensation emerged when the groups occupied asymmetrical positions on one of the two fundamental dimensions and the context was devoid of any conflict. Whenever conflict intruded the intergroup context, we observed a definite propensity to manifest ingroup bias.

As we conjectured, the compensation pattern observed in the critical condition, that is, in asymmetrical relations and in the absence of conflict, seemed to be triggered by different strategies for high- and for low-status groups. Low-status group members appeared to deal with their lack of worth on the manipulated dimension by manifesting ingroup bias on the non-manipulated dimension, a strategy known as social creativity. Members of high-status group displayed 'noblesse oblige' pattern in that they attributed more value to the outgroup on the non-manipulated dimension as a function of their positive evaluation of their ingroup on the manipulated dimension. 
In Study 2, we wanted to replicate and extend these findings by turning our attention to real groups. Although the use of real groups may render the examination of relative status substantially more complex, it is crucial to verify that ecologically valid differences in relative status influence participants' readiness to produce compensatory evaluations of both their ingroup and their outgroup. We therefore decided to examine our potential participants' reactions, all psychology students, with respect to one of a series of selected outgroups varying in status. Specifically, we expected that psychology students would be all the more tempted to demonstrate compensation that the difference in status between groups is large, stable, and legitimate.

In addition to the difference (or degree of asymmetry) in status characterizing the relations between the two groups, we again looked at the impact of conflict on the emergence of compensation. For the sake of generalization, however, we changed the nature of the conflict by using a 'realistic threat' instead of the 'symbolic threat' used in Studies 1a and 1b (Stephan \& Renfro, 2002).

A final goal of Study 2 was to examine more thoroughly the 'noblesse oblige' effect. Indeed, one may wonder why high-status group members should be magnanimous. If their superiority is unquestionable why should they accept to concede some superiority to the outgroup? One possible response lies in the strong normative pressures pertaining to the expression of discrimination that characterizes contemporary societies (Monteith, Deneen, \& Tooman, 1996). We reasoned that, in the situation where the high-status group is clearly superior to the low-status group, high-status group members should be aware of their blatant superiority. Such a difference should likely activate the norm of non-discrimination and, consequently, non-discrimination pressures. As a result, high-status group members may feel embarrassed to express ingroup bias on both fundamental dimensions and may restrict their partisanship to the most critical dimension in the context, i.e., the one on which their 
domination is undeniable. We thus predicted a mediational effect by which the perception of their superiority on one dimension (measured by the ingroup bias on the manipulated dimension) should activate non-discrimination pressures which in turn should affect the expression of outgroup bias on the other dimension.

Method

\section{Participants}

A total of 120 psychology students participated for partial course credit. Four cases were omitted because they doubted the credibility of the manipulation. The final sample consisted of $N=116$. Ages ranged between 18 and 52 years $(M=22.9 ; S D=3.21$; females $=71 \%$ ) .

\section{Procedure and design}

Participants were run in sessions of four or six persons. They were told that they participated in a survey on the future relocation of different departments of the university on campus and that the university wanted to know where each major wished to be located. This cover story was highly credible because at the time of the experiment the university was involved in a relocation process. Participants were also shown the responses given by a sample of other majors. This procedure was used to manipulate the distance between the outgroup relative to the ingroup such that we had five levels of the independent variable: a very superior ingroup, a slightly superior one, equal ingroup and outgroup, a slightly inferior ingroup, and a very inferior one. This procedure also allowed manipulating the degree of conflict. Indeed, the responses given by the outgroup were (were not) conflicting because the outgroup wanted (did not want) to occupy the psychology department building which enjoyed the reputation of being one of the nicest buildings on campus.

Next, participants filled in the dependent variables as part of the general survey on relocation. More specifically, they were asked to answer the same questions as those used in 
Studies $1 \mathrm{a}$ and $1 \mathrm{~b}$ plus a series of questions related to the legitimacy and stability of the status difference. Finally, participants were debriefed

The experiment adopted a 2 (conflict: high vs. low) x 5 (ingroup status: very superior vs. slightly superior vs. equal vs. slightly inferior vs. very inferior) factorial design.

\section{Materials}

The groups used to manipulate the status of the ingroup relative to the outgroup were auxiliary nurse, special education teacher, sociology, economy, and, medical majors for, respectively, the very superior, slightly superior, equal status, slightly inferior, and very inferior ingroup conditions. They were selected on the basis of a pretest so as to significantly differ among them on the status dimension and, with the exception of the equal status condition, also significantly differ from the psychology major.

\section{Measures}

The dependent variables were the same as in Studies 1a and 1b with three exceptions. Firstly, there was one change of item in the measure of the perception of conflict ( $\alpha=.94)$. Second, we also measured the perceived status of the ingroup relative to the outgroup ('In the hierarchy of majors, what is the level occupied by psychology majors relatively to X majors?') as well as the legitimacy and stability of the status difference between the groups ('Do you think that the status difference between $\mathrm{X}$ majors and psychology majors is legitimate/stable?') on 9-point scales ranging from 1 (= very inferior/very illegitimate/very unstable) to 9 (= very superior/very legitimate/very stable). The highly significant correlation between the items related to legitimacy and stability, $r=.78, p<.0001$, allowed creating an index of illegitimacy by reversing and averaging the two items ${ }^{3}$.

Finally, a series of questions dealt with the perception of pressures toward nondiscrimination (e.g., 'Is it acceptable to express a negative attitude toward the other group?') on 9-point scales with 1 (9) corresponding to a weak (strong) perception of pressures $(\alpha=.71)$. 
They were adapted from the external motivation to respond without prejudice items of Plant and Devine (2001) and were checked for their validity with a sample of 20 psychology students.

Results

\section{Preliminary analyses}

A 2 (conflict: high vs. low) x 5 (ingroup status: very inferior vs. slightly inferior vs. equal vs. slightly superior vs. very superior) ANOVA revealed the main effect of status, $F(4,106)=125.29, p<.001$, confirming the success of the status manipulation. Follow-up paired comparisons showed that students perceived each group as having a status that was significantly different from the status of the others $\left(M_{\text {very inferior }}=2.63, M_{\text {slightly inferior }}=4.09\right.$, $\left.M_{\text {equal }}=5.21, M_{\text {slightly superior }}=5.65, M_{\text {very superior }}=6.87\right)$. Moreover, the equal status group was perceived as having the same status than the psychology group as revealed by a Student $t$ test comparing the mean of the equal-status group and the middle of the status scale $(5$, meaning that the outgroup has the same status than the ingroup), $t(23)=-1.16, n s)$.

We submitted the conflict score to the same ANOVA. Our manipulation of conflict proved effective, $F(1,106)=342.68, p<.001$, because participants perceived the situation as more conflicting in the high $(M=6.38)$ than in the low conflict conditions $(M=3.81)$. There was also a significant status main effect, $F(4,106)=23.45, p<.001$. Follow-up paired comparisons revealed that the perception of conflict was lowest for the very superior, the very inferior, and the equal status conditions, which did not differ among them, and highest for the slightly superior and slightly inferior conditions, which again did not differ among them $\left(M_{\text {very inferior }}=4.27, M_{\text {slightly inferior }}=5.60, M_{\text {equal }}=4.75, M_{\text {slightly superior }}=6.04, M_{\text {very superior }}=4.67\right) . \mathrm{A}$ significant interaction, $F(4,106)=16.52$, $p<.001$, confirmed that this pattern was less present in the context of high conflict. Not surprisingly, the perceived level of conflict was more homogeneously reported to be high in the case of high as opposed to low conflict. 


\section{Compensation versus ingroup bias}

We expected compensation to emerge more readily with asymmetrical intergroup relations and with a low level of conflict. In contrast, ingroup bias should show up across the board when a high level of conflict intrudes the intergroup relations.

We tested these predictions by capitalizing on the same index of compensation and ingroup bias as used in Studies 1a and 1b. As before, because the two indices were strongly correlated, $r(116)=-.44, p<.001$, and because their analyses led to identical conclusions, we created an index of preference for compensation by subtracting the measure of ingroup bias from the measure of compensation. This preference index was submitted to a 2 (conflict: high vs. low) x 5 (ingroup status: very inferior vs. slightly inferior vs. equal vs. slightly superior vs. very superior) ANOVA.

All effects were significant (see Table 2 for raw means). The conflict main effect, $F(1,106)=222.58, p<.001$, revealed that the high conflict condition generated a preference for ingroup bias $(M=-2.45)$ whereas the low conflict condition allowed a preference for compensation $(M=2.43)$. The status main effect, $F(4,106)=8.77, p<.001$, confirmed that the preference for compensation differed as a function of the status difference (see Figure 1). A series of four orthogonal contrasts indicated that both the linear and the quadratic contrasts were significant, $F(1,106)=6.60, p<.02$, and $F(1,106)=28.68, p<.001$, respectively. Importantly, a significant omnibus conflict by status interaction, $F(4,106)=8.00, p<.001$, suggested that the status main effect was moderated by the level of conflict between the groups. We found a significant interaction of status with the linear as well as with the quadratic contrast, $F(1,106)=11.45, p<.001$, and $F(1,106)=15.80, p<.001$, respectively.

To further probe these interactions, we examined the linear and quadratic contrasts separately for each level of conflict. Whereas only the quadratic contrast proved significant when the level of conflict was low, $F(1,106)=44.55, p<.001$, the linear contrasts was the only 
one to be significant in the presence of a high level of conflict, $F(1,106)=17.17, p<.001$. As shown in Figure 1, a preference for compensation emerged when there was a large difference in status between the groups and the level of conflict was low. In sharp contrast, ingroup bias was preferred when there was a high level of conflict. Interestingly, ingroup bias was definitely more prevalent when the outgroup had a higher status than the ingroup. Said otherwise, the intrusion of intergroup conflict made the prevailing preference for compensation disappear altogether, especially in those situations where there was a marked asymmetry between the groups, and allowed a preference for ingroup bias to emerge instead, particularly when the status of the ingroup was lower than that of the outgroup.

\section{Legitimacy and stability}

In order to check if status difference influenced legitimacy as expected, we first compared the pattern of results obtained for the illegitimacy score. Next, we performed a mediational analysis treating illegitimacy as our variable mediating the impact of the status difference on the preference for compensation.

We submitted the illegitimacy index to a 2 (conflict: high vs. low) x 5 (ingroup status: very inferior vs. slightly inferior vs. equal vs. slightly superior vs. very superior) ANOVA. The conflict main effect, $F(4,106)=149.59, p<.001$, and the ingroup status one, $F(4,106)=22.00, p<.001$, were significant. Probing the differences of the status main effect with paired comparisons between the five means revealed that the perception of illegitimacy was highest for the slightly superior and slightly inferior conditions, and lowest for the very superior, very inferior, and equal status conditions $\left(M_{\text {very inferior }}=2.92, M_{\text {slightly inferior }}=4.57\right.$, $\left.M_{\text {equal }}=3.44, M_{\text {slightly superior }}=4.72, M_{\text {very superior }}=3.59\right)$. The significant conflict by ingroup status interaction, $F(4,106)=10.49, p<.001$, revealed that this pattern was present only in the low conflict condition. With the exception of the equal-status position, the status positions which produced a preference for compensation (very inferior and very superior) are also those which 
appeared as the most stable and legitimate. In contrast, a general perception of illegitimacy prevailed when the level of conflict was high, setting ground for a preference for ingroup bias.

We restricted the mediational analyses to the very superior, slightly superior, slightly inferior and very superior ingroups, excluding the equal status ingroup because we did not expect compensation for this group and indeed none emerged. We computed two mediational analyses, in the low and in the high conflict condition, with the perceived status difference ${ }^{4}$ as our independent variable, the illegitimacy index as our mediator, and the preference for compensation as our dependent variable. We hypothesized that the perception of illegitimacy mediated the relation between the perception of status difference and the preference for compensation in low but not in high conflict conditions. In the low conflict condition, the total effect proved significant, $b=0.70, t(46)=3.38, p<.001$ (Figure 2, upper panel). When the mediator was included in the model, the direct effect became non-significant, $b=0.28$, $t(45)=1.21, p=.23$. The drop was significant, as evidenced by a significant Sobel test, $z=2.59$, $p<.01$. In the high conflict condition (Figure 2, lower panel), the total effect was not significant, $b=0.50, t(42)=1.34, p=.19$.

\section{The 'Noblesse oblige' effect}

We tested our mediational hypothesis related to the role of pressures toward nondiscrimination in the 'noblesse oblige' pattern'. We performed a mediational analysis with ingroup bias on the competence dimension as our independent variable, ingroup bias on the warmth dimension as our dependent variable, and pressures toward non-discrimination as our mediator. Because restricting the analysis to the very superior ingroup condition lead to the inclusion of an unduly limited number of participants, we considered both conditions where psychology students belonged to a high-status group, namely the slightly superior and very superior conditions. The total effect proved significant, $b=-0.67, t(22)=-4.21, p<.001$ (Figure 3, upper panel). When the mediator was included in the model, the direct effect dropped to 
non-significance, $b=-0.24, t(21)=-1.70, n s$. This drop was significant, as evidenced by a significant Sobel test, $z=-2.97, p<.005$. In contrast, when participants faced an inferior group in a high conflict context (Figure 3, lower panel), the total effect proved significant but was positive, $b=.43, t(20)=2.14, p<.05$. When the mediator was included in the model, the relation between independent and dependent variable remained largely unaffected, $b=0.49, t(19)=2.05$, $p<.06$ (Sobel test, $z=-0.45, n s)$.

Discussion

Study 2 sends several important messages. First and foremost, the data corroborate the lessons from Studies $1 \mathrm{a}$ and $1 \mathrm{~b}$ in that both status differences and level of conflict contribute to the emergence of compensation. In contrast, symmetrical and conflicting relations tend to generate ingroup bias on both dimensions. As in Studies $1 \mathrm{a}$ and $1 \mathrm{~b}$, symmetrical relations characterized by a relative absence of conflict make both ingroup bias and compensation less likely. Study 2 also suggests that the perception of illegitimacy stands as a possible factor that explains this effect.

Another important contribution of Study 2 is the mediational role of pressures toward non-discrimination as a variable mediating the relation of the ingroup bias on competence and an outgroup bias on warmth. As in Studies 1a and 1b, the presence of intergroup conflict annihilated this phenomenon. In fact, when the groups were in conflict, the high-status group showed a clear ingroup bias on both dimensions.

\section{General Discussion}

In the context of recent work on the compensation pattern, the present studies shed light on key structural and psychological processes of the compensation effect.

\section{The structural constraints: Status differences and intergroup conflict}

We predicted and showed that participants' evaluations of the ingroup and the outgroup showed a compensation pattern only in the absence of intergroup conflict and when 
there was an asymmetry in group positions. When groups were in a symmetrical relation, compensation gave way to ingroup bias, the intensity of which depended on the conflicting nature of the relation. These results were obtained in a minimal context (Studies 1a \& 1b) but also in the context of real groups (Study 2).

A most interesting lesson emanating from Study 2 is that the perception of legitimacy and stability mediated the link between status difference and preference for compensation. Specifically, the present data suggest that the perception of status difference generates inferences about the legitimacy of the social hierarchy which in turn affects the strategy that group members use to handle the situation. Clearly, they rely on compensation if the distance between the groups is large and appears as legitimate. In contrast, ingroup bias is the preferred option if the intergroup distance is low and appears as illegitimate.

Of course, the above findings should be taken with some caution given that the correlational status of the legitimacy variable leaves open the door for an alternative explanation. One possible candidate is distinctiveness. As shown by Jetten, Spears, and Manstead (1998), the relation between differentiation and distinctiveness is curvilinear with a maximum of differentiation when group distinctiveness is moderate. Using this theoretical framework, it is possible to interpret our manipulation of distance between the groups as a reflection of varying degrees of distinctiveness going from low distinctiveness (equal status condition) to high distinctiveness (very superior or very inferior status conditions) with moderate distinctiveness (superior or inferior status conditions) in between. So, it is possible to interpret the lower preference for compensation (in favor of ingroup bias) manifested by groups that are only moderately distinct from the outgroup in terms of an optimum level of distinctiveness. It seems prudent to manipulate the legitimacy of status relations in future studies to properly examine the underlying processes (Oldmeadow \& Fiske, 2012).

The subjective underpinnings of compensation 
Our analysis led us to predict that the underlying mechanisms allowing compensation to emerge are likely to differ as a function of one's position in the social hierarchy. For those at the bottom of the social ladder, we expected and showed that the more members of lowstatus groups favored their ingroup on warmth, the more they favored the outgroup on competence. Interestingly enough, the intrusion of a high level of conflict made it more difficult for participants to fall back on social creativity to accommodate the superiority of the outgroup on the competence dimension.

Turning to the people on top of the social hierarchy, Studies 1a and 1b showed, as predicted, that they were all the more willing to concede high levels of warmth to the lowstatus group that they saw their own group as being competent. Moreover, this 'noblesse oblige' pattern only appeared in the absence of conflict condition and, of course, in the presence of a status difference. Study 2 further revealed that this 'noblesse oblige' effect was mediated by people's sensitivity to pressures toward non-discrimination. Again, conflict had this pattern disappear. To be sure, future experiments should directly manipulate pressures toward discrimination in order to establish its causal role as a mediating variable (Spencer, Zanna, \& Fong, 2005).

\section{Future directions}

Several avenues for future research present themselves. A first line of research may focus further on the impact of structural conditions on the emergence of compensation. For instance, the permeability of group boundaries is probably a factor affecting the emergence of compensation. Indeed, in accordance with the theoretical predictions of Tajfel and Turner (1979), a meta-analysis by Bettencourt et al. (2001) showed that when group boundaries are permeable, and independently of the legitimacy or stability of the status structure, members of low-status groups dissociate from their ingroup and adopt an individual upward mobility strategy whereas members of high-status affirm their superiority in an effort to defend their 
group boundaries. In contrast, when group boundaries are impermeable, low-status groups adopt collective and more competitive strategies to achieve positive identity, especially when the status structure is illegitimate. By securing the superiority of high-status over low-status ones, the impermeability of group boundaries lessens the motivation of high-status group members to positively differentiate their group.

These conclusions suggest a series of interesting predictions with respect to the compensation pattern. For example, it could be argued that when group boundaries are permeable compensation is less likely to appear. As a matter of fact, low-status groups should be tempted to positively value high-status groups on both dimensions whereas high-status groups should likely favor their ingroup on both dimensions. In the case of impermeability, one would anticipate systematic ingroup bias from low-status groups, at least when the social structure is illegitimate. When the social structure is more legitimate, one may expect lowstatus groups to manifest ingroup bias on the dimension that best defines their identity (warmth) but they should acknowledge the superiority of the high-status group on the other dimension (competence). In short, the joint presence of impermeability and legitimacy should encourage low-status groups to manifest a compensation pattern. In this same situation and as far as high-status groups are concerned, compensation would seem like a probable strategy simply because their domination is undisputed. Interestingly, the results obtained in the present studies are more in line with the predictions we would make about a situation where group boundaries are perceived as impermeable. This suggests that our psychology students considered that changing their low-status major into a high-status one is a difficult endeavor.

As compensation is a strategy allowing the search for distinctiveness on one dimension at the expense of the other, a second interesting direction to pursue would be to look at the extent to which warmth and competence perceptions become normatively defining for the groups. Thus, instead of focusing on the content of the stereotype associated with 
different groups, it would be interesting to consider either the importance each group attribute with respect to the different dimensions or the consensus in the group definitions (Haslam, Turner, Oakes, Reynolds, Eggins, Nolan, and Tweedie, 1998). One reasonable prediction would be that low-status groups exhibit a higher level of consensus and give more importance to the warmth dimension whereas high-status group should stress the importance of and agree more on competence traits.

\section{Conclusion}

As a set, our findings suggest that compensation emerges at early stages of the existence of a group and persists in groups with a real history and a group life. They also imply that compensation is not restricted to groups that are the target of widespread stereotypes but that it materializes as soon as people notice a difference in status. The fact that we obtained compensation with real groups is also an argument in favor of the fact that compensation is not some sort of artefact obtained in vitro. However, the prevalence of compensation should not be exaggerated and should not encourage seeing intergroup relations with pink glasses. Indeed, the present efforts emphasize that signs of dispute or perception of threat have compensation recede and ingroup bias rule instead. 


\section{References}

Bettencourt, B. A., \& Bartholow, B. D. (1998). The importance of status legitimacy for intergroup attitudes among numerical minorities. Journal of Social Issues, 54, 759775. doi: 10.1111/j.1540-4560.1998.tb01247.x

Bettencourt, B. A., Dorr, N., Charlton, K., \& Hume, D. L. (2001). Status differences and ingroup bias: A meta-analytic examination of the effects of status stability, status legitimacy, and group permeability. Psychological Bulletin, 127, 520-542. doi:10.1037/0033.2909.127.4.520

Brewer, M. B., Manzi, J. M., \& Shaw, J. S. (1993). In-group identification as a function of depersonalization, distinctiveness, and status. Psychological Science, 4, 88-92. doi: 10.1111/j.1467-9280.1993.tb00466.x

Cuddy, A.J.C., Fiske, S.T., \& Glick, P. (2008). Warmth and competence as universal dimensions of social perception: The stereotype content model and the BIAS map. In M.P. Zanna (Ed.), Advances in Experimental Social Psychology (pp. 61-149). San Diego, Elsevier Academic Press. doi: 10.1016/S0065-2601(07)00002-0

Ellemers, N., \& Van Rijswijk, W. (1997). Identity needs versus social opportunities: The use of group-level and individual-level identity management strategies. Social Psychology Quarterly, 60, 52-65. doi: 10.2307/2787011

Fiske, S.T., Cuddy, A.J.C., \& Glick, P. (2007). Universal dimensions of social perception: warmth, then competence. Trends in Cognitive Science, 11, 77-83. doi:10.1016/j.tics.2006.11.005

Haslam, A.S., Turner, J.C., Oakes, P.J., Reynolds, K.J, Eggins, R.A., Nolan, M., and Tweedie, J. (1998). When do stereotypes become really consensual? Investigating the group-based dynamics of the consensualization process. European Journal of Social 
Psychology, 28, 755-776. doi: 10.1002/(SICI)1099-0992(199809)28:5<755::AIDEJSP891>3.0.CO;2-Z

Jetten, J., Spears, R., \& Manstead, S.R. (1998). Defining dimensions of distinctiveness: Group variability makes a difference to differentiation. Journal of Personality and Social Psychology, 74, 1481-1492. doi: 10.1037//0022-3514.74.6.1481

Judd, C., James-Hawkins, L. Yzerbyt, V., \& Kashima, Y. (2005). Fundamental dimensions of social judgment: Understanding the relations between judgments of competence and warmth. Journal of Personality and Social Psychology, 89, 899-913. doi: 10.1037/0022-3514.89.6.899

Kervyn, N., Yzerbyt, V., \& Judd, C. (2010). Compensation between warmth and competence: Antecedents and consequences of a negative relation between the two fundamental dimensions of social perception. European Review of Social Psychology, 21, 155-187. doi: 10.1080/13546805.2010.517997

Monteith, M.J., Deneen, N.E., \& Tooman, G.D. (1996). The effect of social norm activation on the expression of opinions concerning gay men and blacks. Basic and Applied Social Psychology, 18, 267-288. doi: 10.1207s15324834basp1803_2

Mullen, B., Brown, R., \& Smith, C. (1992). Ingroup bias as a function of salience, relevance, and status: An integration. European Journal of Social Psychology, 22, 103-122. doi: 10.1002/ejsp.2420220202

Oldmeadow, J.A., \& Fiske, S.T. (2010). Social status and the pursuit of positive social identity: Systematic domains of intergroup differentiation and discrimination for highand low-status groups. Group Processes and Intergroup Relations, 13, 425-444. doi: $10.1177 / 1368430209355650$ 
Oldmeadow, J.A., \& Fiske, S.T. (2012). Contentment to resentment: Variation in stereotype content across status systems. Analyses of Social Issues and Public Policy, 12, 324339. doi: 10.1111/j.1530-2415.2011.01277.x

Plant, E. A., \& Devine, P. G. (2001). Responses to other - imposed pro - Black pressure: Acceptance or backlash? Journal of Experimental Social Psychology, 37, 486-501. doi: 10.1006/jesp.2001.1478

Reichl, A. J. (1997). Ingroup favoritism and outgroup favoritism in low status minimal groups: Differential responses to status-related and status-unrelated measures. European Journal of Social Psychology, 27, 617-633. doi: 10.1002/(SICI)10990992(199711/12)27:6<617::AAID-EJSP829>3.3.CO;2-K

Richetin, J., Durante, F., Mari, S., Perugini, M., \& Volpato, C. (2012). Primacy of warmth versus competence : A motivated bias ? The Journal of Social Psychology, 152, 417435. doi: $10.1080 / 00224545.2011 .623735$

Sachdev, I., \& Bourhis, R. Y. (1985). Social categorization and power differentials in group relations. European Journal of Social Psychology, 15, 415-434. doi: 10.1002/ejsp.2420150405

Spencer, S. J., Zanna, M. P., \& Fong, G. T. (2005). Establishing a causal chain: Why experiments are often more effective than mediational analyses in examining psychological processes. Journal of Personality and Social Psychology, 89, 845-851. doi:10.1037/0022-3514.89.6.845

Stephan, W. G., \& Renfro, C. L. (2002). The role of threats in intergroup relations (pp. 191208). In D. Mackie \& E. R. Smith (Eds.), From prejudice to intergroup emotions . New York: Psychology Press. doi: 10.1002/9781444303117.ch5

Tajfel. H. (1981). Human groups and social categories. Cambridge, England: Cambridge University Press. 
Tajfel, H., \& Turner, J. C. (1979). An integrative theory of intergroup conflict. In W. G. Austin \& S. Worchel (Eds.), The Social Psychology of intergroup relations (pp. 3347). Chicago: Nelson-Hall.

Terry, D.J. (2003). A social identity perspective on organizational mergers: The role of group status, permeability, and similarity. In A.S. Haslam, D. van Knippenberg, M.J. Platow, \& N. Ellemers (Eds). Social Identity at work: Developing theory for organizational practice (pp. 223-240). New York, Psychology Press.

Turner, J. C. (1999). Some current issues in research on social identity and self-categorization theories. In N. Ellemers, R. Spears, \& B. Doosje (Eds.), Social identity: Context, commitment, content (pp. 6-34). Oxford, England: Blackwell.

Turner. J. C., \& Brown, R. (1978). Social status, cognitive alternatives, and intergroup relations. In H. Tajfel (Ed.), Differentiation between social groups: Studies in the social psychology of intergroup relations (pp. 202-234). New York: Academic Press.

Vanbeselaere, N., Boen, F., van Avermaet, E., \& Buelens, H. (2006). The Janus face of power in intergroup contexts: A further exploration of the noblesse oblige effect. The Journal of Social Psychology, 146, 685-699. doi: 10.3200/SOCP.146.6.685-699

van Knippenberg, A.F. (1984). Intergroup differences in group perceptions. In H. Tajfel (Ed.) The social dimension (vol. 2, pp. 560-578). Cambridge, Cambridge university press. van Knippenberg, A., \& Ellemers, N. (1990). Social identity and intergroup differentiation processes. European Review of Social Psychology, 1, 137-169. doi: $10.1080 / 14792779108401860$

Vaughan, G. M. (1978). Social change and intergroup preferences in New Zealand. European Journal of Social Psychology, 8, 297-314. doi: 10.1002/ejsp.2420080304 
Yzerbyt, V. Y., \& Demoulin, S. (2010). Intergroup relations. In S. T. Fiske, D. T. Gilbert, \& G. Lindzey (Eds.), The Handbook of Social Psychology (5th edition, Vol. 2, pp. 10241083). Hoboken, NJ: Wiley.

Yzerbyt, V., Kervyn, N., \& Judd, C. (2008). Compensation versus halo: The unique relations between the fundamental dimensions of social judgment. Personality and Social Psychology Bulletin, 34, 1110-1123. doi: 10.1177/0146167208318602

Yzerbyt, V., Provost, V., \& Corneille, O. (2005). Not so competent but warm... Really? Compensatory stereotypes in the French-speaking world. Group Processes and Intergroup Relations, 8, 291-308. doi: 10.1177/1368430205053944 
Tables

Table 1a. Ratings as a function of conflict, intergroup relation, dimension, ingroup status, and target group (Study 1a: manipulation of competence)

\section{Conflict}

Absence of Conflict Presence of Conflict

\begin{tabular}{|c|c|c|c|c|c|c|c|c|}
\hline \multirow{2}{*}{$\begin{array}{l}\text { Relation } \\
\text { Dimension }\end{array}$} & \multicolumn{2}{|c|}{ Asymmetrical } & \multicolumn{2}{|c|}{ Symmetrical } & \multicolumn{2}{|c|}{ Asymmetrical } & \multicolumn{2}{|c|}{ Symmetrical } \\
\hline & $\mathrm{C}$ & $\mathrm{W}$ & $\mathrm{C}$ & $\mathrm{W}$ & $\mathrm{C}$ & $\mathrm{W}$ & $\mathrm{C}$ & $\mathrm{W}$ \\
\hline \multicolumn{9}{|l|}{ High Status } \\
\hline Ingroup & $6.14 b$ & $5.05 a$ & $5.41 \mathrm{~b}$ & $5.83 \mathrm{~b}$ & $5.41 \mathrm{~b}$ & $5.42 \mathrm{~b}$ & $6.14 b$ & $5.71 \mathrm{~b}$ \\
\hline Outgroup & $4.73 a$ & $6.30 b$ & $5.18 \mathrm{a}$ & $5.17 \mathrm{a}$ & $3.13 \mathrm{a}$ & $3.92 \mathrm{a}$ & $3.69 \mathrm{a}$ & $3.80 \mathrm{a}$ \\
\hline \multicolumn{9}{|l|}{ Low Status } \\
\hline Ingroup & $5.21 a$ & $6.43 b$ & $5.38 \mathrm{~b}$ & $6.07 \mathrm{~b}$ & $5.05 \mathrm{~b}$ & $5.94 \mathrm{~b}$ & $4.74 b$ & $6.08 \mathrm{~b}$ \\
\hline Outgroup & $6.50 b$ & $5.36 a$ & $5.16 \mathrm{a}$ & $5.78 \mathrm{a}$ & $4.78 \mathrm{a}$ & $3.83 \mathrm{a}$ & $3.33 \mathrm{a}$ & $3.56 \mathrm{a}$ \\
\hline
\end{tabular}

Note: $\mathrm{C}=$ competence, $\mathrm{W}=$ warmth. For each comparison between ingroup and outgroup, means with different subscripts are significantly different at $p<.05$. Numbers in italics indicate the presence of a compensation pattern. 
Table 1b. Ratings as a function of conflict, intergroup relation, dimension, ingroup status, and target group (Study 1b: manipulation of warmth)

\begin{tabular}{|c|c|c|c|c|c|c|c|c|}
\hline \multirow{4}{*}{$\begin{array}{l}\text { Relation } \\
\text { Dimension }\end{array}$} & \multicolumn{8}{|c|}{ Conflict } \\
\hline & \multicolumn{4}{|c|}{ Absence of Conflict } & \multicolumn{4}{|c|}{ Presence of Conflict } \\
\hline & \multicolumn{2}{|c|}{ Asymmetrical } & \multicolumn{2}{|c|}{ Symmetrical } & \multicolumn{2}{|c|}{ Asymmetrical } & \multicolumn{2}{|c|}{ Symmetrical } \\
\hline & $\mathrm{C}$ & $\mathrm{W}$ & $\mathrm{C}$ & $\mathrm{W}$ & $\mathrm{C}$ & $\mathrm{W}$ & $\mathrm{C}$ & $\mathrm{W}$ \\
\hline \multicolumn{9}{|l|}{ High Status } \\
\hline Ingroup & $6.27 a$ & $6.88 b$ & $6.12 \mathrm{a}$ & $6.48 \mathrm{a}$ & $5.63 b$ & $6.23 b$ & $6.19 b$ & $5.67 b$ \\
\hline Outgroup & $6.90 b$ & $5.95 a$ & $6.04 \mathrm{a}$ & $6.44 \mathrm{a}$ & $4.42 \mathrm{a}$ & $3.88 \mathrm{a}$ & $3.78 \mathrm{a}$ & $4.46 \mathrm{a}$ \\
\hline \multicolumn{9}{|l|}{ Low Status } \\
\hline Ingroup & $6.65 b$ & $6.03 a$ & $6.48 \mathrm{a}$ & $6.10 \mathrm{a}$ & $6.28 b$ & $5.57 \mathrm{~b}$ & $6.18 b$ & $6.08 b$ \\
\hline Outgroup & $6.11 a$ & $6.53 b$ & $6.43 a$ & $6.07 \mathrm{a}$ & $3.74 \mathrm{a}$ & $4.47 \mathrm{a}$ & $3.82 \mathrm{a}$ & $4.49 a$ \\
\hline
\end{tabular}

Note: $\mathrm{C}=$ competence, $\mathrm{W}=$ warmth. For each comparison between ingroup and outgroup, means with different subscripts are significantly different at $p<.05$. Numbers in italics indicate the presence of a compensation pattern. 
Table 2. Ratings as a function of level of conflict, dimension, status of the ingroup, and target group (Study 2)

\section{Conflict}

Low

High

Dimension

$\mathrm{C}$

W

$\mathrm{C}$

$\mathrm{W}$

Very Superior

$\begin{array}{lllll}\text { Ingroup } & 7.15 b & 5.33 a & 6.32 \mathrm{~b} & 5.17 \mathrm{~b} \\ \text { Outgroup } & 4.64 a & 7.40 b & 3.71 \mathrm{a} & 4.73 \mathrm{a}\end{array}$

Superior

$\begin{array}{lllll}\text { Ingroup } & 5.51 b & 4.89 a & 5.68 \mathrm{~b} & 5.20 \mathrm{~b} \\ \text { Outgroup } & 4.14 a & 5.64 b & 3.15 \mathrm{a} & 4.23 \mathrm{a}\end{array}$

Equal

$\begin{array}{lllll}\text { Ingroup } & 5.50 \mathrm{a} & 6.21 \mathrm{a} & 4.76 \mathrm{~b} & 5.44 \mathrm{~b} \\ \text { Outgroup } & 5.63 \mathrm{a} & 6.11 \mathrm{a} & 3.28 \mathrm{a} & 4.30 \mathrm{a}\end{array}$

Inferior

$\begin{array}{lllll}\text { Ingroup } & 4.90 a & 6.51 b & 4.92 \mathrm{~b} & 6.10 \mathrm{~b} \\ \text { Outgroup } & 5.92 b & 5.10 a & 4.00 \mathrm{a} & 4.05 \mathrm{a}\end{array}$

Very inferior

$\begin{array}{lllll}\text { Ingroup } & 5.12 a & 7.19 b & 5.61 \mathrm{~b} & 6.05 \mathrm{~b} \\ \text { Outgroup } & 7.31 b & 5.43 a & 5.18 \mathrm{a} & 3.92 \mathrm{a}\end{array}$

Note: $\mathrm{C}=$ competence, $\mathrm{W}=$ warmth. For each comparison between ingroup and outgroup, means with different subscripts are significantly different at $p<.05$. Numbers in italics indicate the presence of a compensation pattern. 


\section{Figure Captions}

Figure 1. Compensation/ingroup bias effect as a function of conflict and the status of the ingroup relative to the outgroup

Figure 2. Perceived illegitimacy as a mediator of the perceived status difference influence on compensation/ingroup index in the low conflict condition (upper panel) and in the high conflict condition (lower panel) (unstandardized regression coefficients, unmediated effects are given in parentheses); ** for $\mathrm{p}<.01$

Figure 3. Perceived pressures toward non-discrimination as a mediator the impact of ingroup bias on competence on ingroup bias on warmth in the two superior and low conflict conditions (upper panel) and in the two superior and high conflict conditions (lower panel) (unstandardized regression coefficients with unmediated effects are given in parentheses); ** for $\mathrm{p}<.05 ; *$ for $\mathrm{p}<.06$ 
Figure 1.

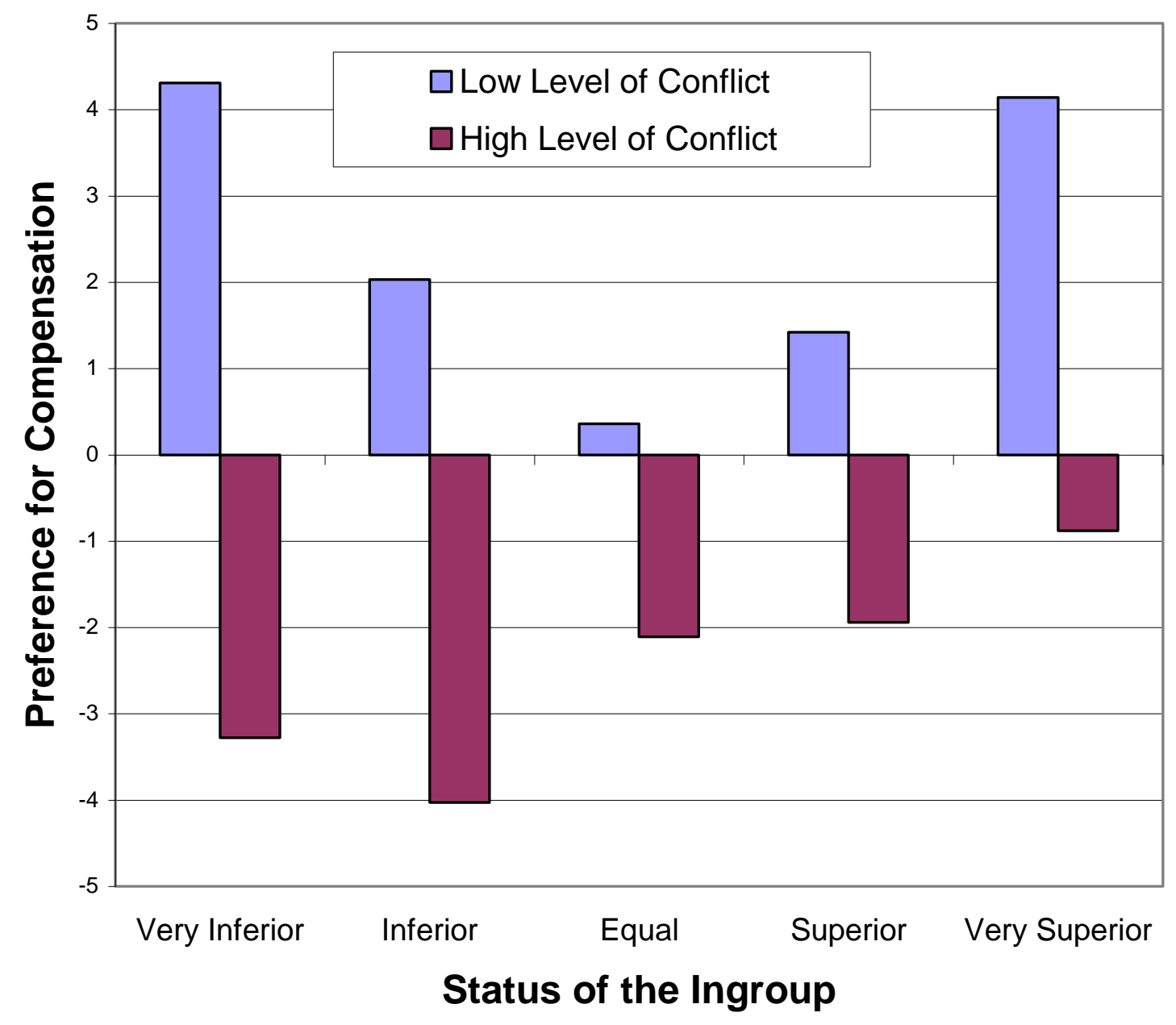


Figure 2.
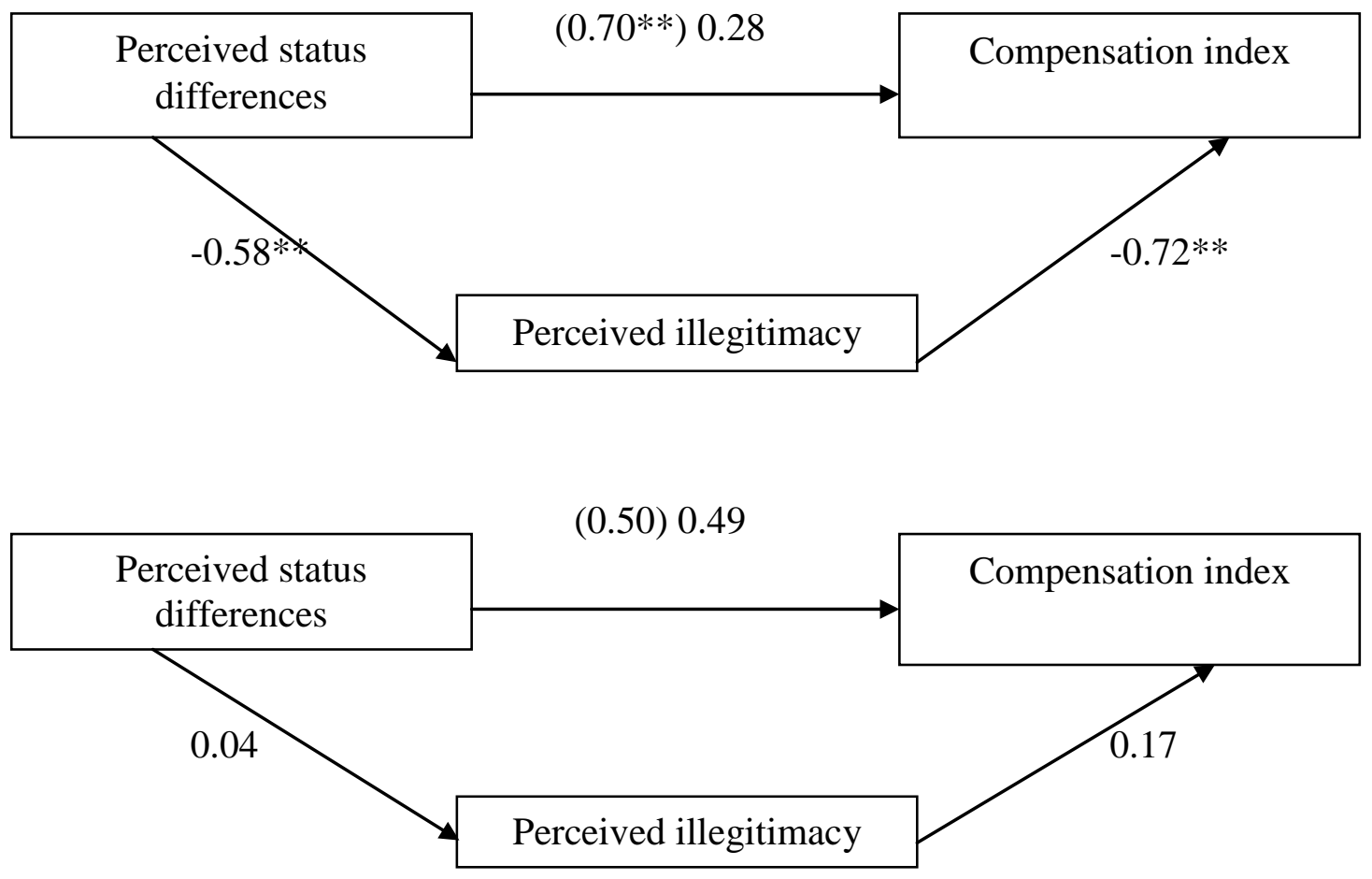
Figure 3.
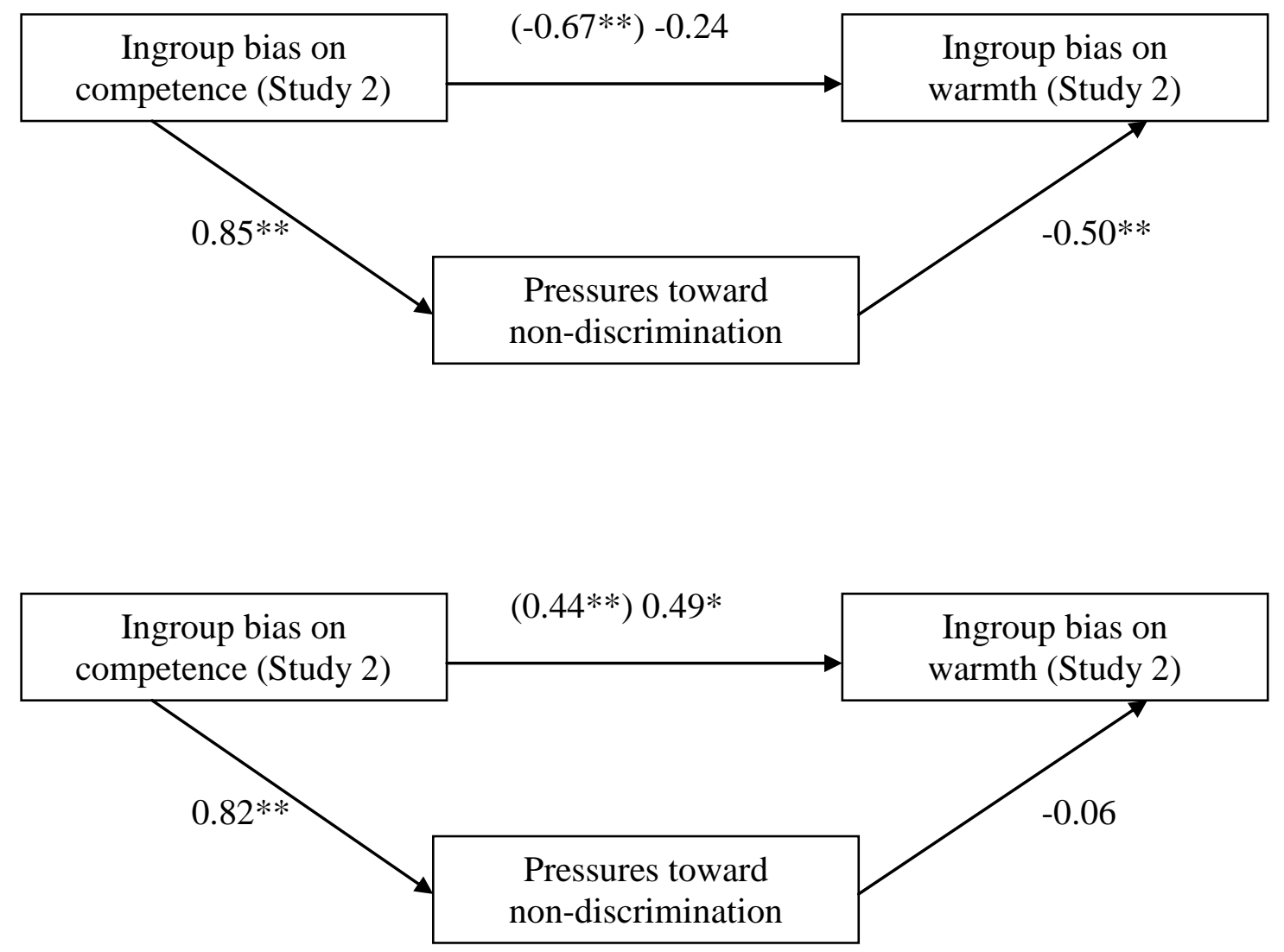


\section{Footnotes}

1. Initially, we assessed participants' ratings on a third dimension, i.e., health; and conducted a third experiment (Study 1c) using health as our manipulated dimension. For the ratings on health in Studies 1a and 1b, the results replicated those obtained by Yzerbyt et al. (2008). Study 1c showed that manipulating health as the dimension of differentiation only triggered ingroup bias and no compensation emerged. As these results were beyond the scope of the research hypotheses tested here, we did not include them. The data can be obtained from the first author upon request.

2. In all studies, measures of identification were included and we examined whether identification moderated the reported effects. In all three studies, identification either did not moderate this relationship or results were inconsistent. However, an interesting effect was obtained for the relationship between preference for compensation and identification in separate regression analyses for the low and conflict conditions. In study $1 \mathrm{a}$ and $1 \mathrm{~b}$, when the relation was not conflicting, the more participants identified with their group the more they compensated $\left(r_{1 \mathrm{a}}=.63, F(1,84)=55.24, p<.001 ; r_{1 \mathrm{~b}}=.33, F(1,82)=9.93, p<.01\right)$. These regressions became non-significant when the relation was conflicting. In study 2 , in the absence of conflict, there was a marginally significant positive relationship $(r=.22$, $F(1,58)=3.01, p=.09)$. This relationship was not significant in the high conflict conditions. The data can be obtained from the first author upon request.

3. Theoretically, stability and legitimacy are independent construct. Still, as outlined by Tajfel (1981), "there is little doubt that an unstable system of social divisions between groups is more likely to be perceived as illegitimate than a stable one; and that conversely a system perceived as illegitimate will contain the seeds of instability" (p. 250). Moreover, empirically, these concepts often covary. For example, Bettencourt et al. (2001) in their metaanalysis reported a correlation of .61 . 
4. We transformed the perception of the status difference variable because this measure was problematic in that it conveys the difference between two groups with a different score when this difference is seen from the perspective of a low-status group (a score going from 1 to 5) or from the perspective of a high-status group (a score going from 5 to 9) thus preventing the use of correlational analyses to examine the link between status difference and any other measure implying a linear bipolar construct (as it is the cases for perception of legitimacy and the preference for compensation index). Thus, in order to secure the equivalence between the perceptions of the status difference of low-status groups on the one hand and high-status groups on the other, we computed, for each participant, the difference between his/her perception of the status and the midpoint of the scale (5) in absolute terms.

5. In Study 2, we also computed the correlations in relation with the social creativity strategy and noblesse oblige effect. We did not present them because they relied on too few participants $(N=12)$. 